RE: Cates JR, Young DN, Guerriero DJ, Jahn WT, Armine JP, Korbett AB, et al: Independent guideline appraisal summary report for Guidelines for Chiropractic Quality Assurance and Practice Parameters (Mercy). Journal of Chiropractic Medicine 2002;1(2):70-71 and Cates JR, Young DN, Guerriero DJ, Jahn WT, Armine JP, Korbett AB, et al: Independent guideline appraisal summary report for Vertebral Subluxation in Chiropractic Practice (CCP) guidelines. Journal of Chiropractic Medicine 2002;1(2):72-74.

\section{To the editor;}

I was surprised to see these 2 articles published in the Journal of Chiropractic Medicine. The articles appear to be derived from a paper previously published in the Journal of Manipulative and Physiological Therapeutics. (1) Guidelines for Authors (2) submitting manuscripts to the Journal of Chiropractic Medicine state, inter alia, "Manuscripts are accepted for consideration to publish with the understanding that they represent original, unpublished work or thoughts, submitted solely to Journal of Chiropractic Medicine."

Dr. Cates and colleagues (1) are to be commended for creative C.V. building. Where there was once a single publication, now there are three. Apparently they have discovered a new measurement in the field of scholarly literature, the "minimum publishable unit (MPU)." I propose that the eponym "Cates" be applied to the MPU.

Since I have already voiced my concerns about the limitations in their methodology, and the composition of their expert panel in another journal, (3) I will simply refer interested readers to that citation.

Meanwhile, we will have to wait and see if the MPU has indeed been realized, or if another publication will carry four papers derived from the same work.

$$
\begin{array}{r}
\text { Christopher Kent, D.C. } \\
\text { President } \\
\text { Council on Chiropractic Practice } \\
195 \text { N. Franklin Turnpike } \\
\text { Ramsey, NJ 07446 } \\
\text { E-mail: cbkent@ix.netcom.com }
\end{array}
$$

\section{REFERENCES}

1. Cates JR, Young DN, Guerriero DJ, Jahn WT, Armine JP, Korbett AB, et al: Evaluating the quality of clinical practice guidelines. J Manipulative Physiol Ther 2001;24:170-76.

2. Guidelines for authors. J Chiropr Med 2002;1: page not numbered.
3. Kent C. Evaluating the quality of clinical practice guidelines (letter). J Manipulative Physiol Ther 2001;24:612-8.

\section{In Response:}

Our recent reports $(1,2)$ are consistent with the overall purpose, policies and instructions of the Journal of Chiropractic Medicine (3) as evidenced by their acceptance for publication after the standard review process. Dr. Kent is incorrect in his conclusion that these reports are duplicative in nature. Our project involved the identification and testing of a guideline analysis instrument and, secondarily, evaluation of chiropractic guidelines using that instrument. Our first paper (4), dealt primarily with the reliability and validity of the Cluzeau et al guideline evaluation instrument (5), and the 2 recent reports concern detailed individual guideline evaluation outcomes for the Mercy and CCP guidelines. $(1,2)$ While these papers share a common topic, it is quite evident that each conclusion occurs after a review of all the documentation. Additional research on chiropractic guideline quality is forthcoming.

$$
\begin{array}{r}
\text { Jeffrey R. Cates, DC, MS, DABCO } \\
200 \text { N. 6th St. } \\
\text { Oregon, IL 61061 }
\end{array}
$$
Email: cates@essexl.com

David N. Young, PhD, DC David J. Guerriero, DC, MS Warren T. Jahn, DC, MPS Jesse P. Armine, RN, DC Alan B. Korbett, DC, DO Daniel S. Bowerman, DC Robert C. Porter, MD Terry D. Sandman, DC, MPH Robert A. King, DC

\section{REFERENCES}

1. Cates JR, Young DN, Guerriero DJ, Jahn WT, Armine JP, Korbett AB, et al. Independent Guideline Appraisal Summary Report for Vertebral Subluxation in Chiropractic Practice (CCP) Guidelines. J Chiropr Med 2002;1: $70-1$.

2. Cates JR, Young DN, Guerriero DJ, Jahn WT, Armine JP, Korbett AB, et al. Independent Guideline Appraisal Summary Report for Guidelines for Chiropractic Quality Assurance and Practice Parameters (Mercy). J Chiropr Med 2002;1:70-1.

3. Guidelines for authors. J Chiropr Med 2002;1: page not numbered.

4. Cates JR, Young DN, Guerriero DJ, Jahn WT, Armine JP, Korbett AB, et al. Evaluating the quality of clinical practice guidelines. J Manipulative Physiol Ther 2001;24:170-6.

5. Cluzeau F, Littlejohns P, Grimshaw J, Feder G. Appraisal instrument for clinical guidelines. London: St. George's Hospital Medical School; May 1997. 